\title{
Kinetic of Water Diffusion and Color Stability of a Resin Composite as a Function of the Curing Tip Distance
}

\author{
Nádia da Rocha Svizero ${ }^{\mathrm{a}}$, Roberta Caroline Bruschi Alonso ${ }^{\mathrm{b}}$, Linda Wang ${ }^{\mathrm{c}}$, \\ Regina Guenka Palma-Dibb ${ }^{\mathrm{d}}$,Maria Teresa Attac, Paulo Henrique Perlatti D’Alpino ${ }^{\mathrm{b} *}$ \\ ${ }^{\mathrm{a}}$ Hospital for Rehabilitation of Craniofacial Anomalies, University of São Paulo - USP, \\ Rua Sílvio Marchione 3-20, Vila Universitária, CEP 17012-900, Bauru, SP, Brazil \\ ${ }^{\mathrm{b} B i o m a t e r i a l s ~ R e s e a r c h ~ G r o u p, ~ A n h a n g u e r a-B a n d e i r a n t e ~ U n i v e r s i t y ~ o f ~ S a ̃ o ~ P a u l o ~-~ U N I B A N, ~}$ \\ Rua Maria Cândida, 1813, Vila Guilherme, CEP 02071-013, São Paulo, SP, Brazil \\ 'Department of Operative Dentistry, Endodontics and Dental Materials, Bauru School of Dentistry, \\ University of São Paulo - USP, Alameda Otávio Pinheiro Brisolla, 9-75, Vila Universitária, \\ CEP 17012-101, Bauru, SP, Brazil \\ ${ }^{\mathrm{d}}$ Department of Restorative Dentistry, Ribeirão Preto School of Dentistry, University of São Paulo - USP, \\ Av. do Café, s/n, Monte Alegre, CEP 14040-904, Ribeirão Preto, SP, Brazil
}

Received: March 5, 2012; Revised: May 3, 2012

\begin{abstract}
The influence of curing tip distance and storage time in the kinetics of water diffusion (water sorption- $\mathrm{W}_{\mathrm{SP}}$, solubility- $\mathrm{W}_{\mathrm{SB}}$, and net water uptake) and color stability of a composite were evaluated. Composite samples were polymerized at different distances $(5,10$, and $15 \mathrm{~mm})$ and compared to a control group $(0 \mathrm{~mm})$. After desiccation, the specimens were stored in distilled water to evaluate the water diffusion over a 120-day period. Net water uptake was calculated (sum of WSP and WSB). The color stability after immersion in a grape juice was compared to distilled water. Data were submitted to three-way ANOVA/Tukey's test $(\alpha=5 \%)$. The higher distances caused higher net water uptake $(p<0.05)$. The immersion in the juice caused significantly higher color change as a function of curing tip distance and the time $(\mathrm{p}<0.05)$. The distance of photoactivation and storage time provide the color alteration and increased net water uptake of the resin composite tested.
\end{abstract}

Keywords: composite resins, polymerization, absorption, solubility, color

\section{Introduction}

Recent improvements in resin-based dental materials have focused on the longevity of restorations not only considering the mechanical resistance but also their chemical stability. Currently, many discussions in the literature address the degradation ${ }^{1}$, color-change ${ }^{2,3}$, and leaching of monomers after simulated aging in various solvents, including saliva, water, and ethanol ${ }^{4,5}$. Water absorption was previously deemed beneficial to filling materials, as the consequent swelling was believed to compensate for polymerization shrinkage ${ }^{6}$. However, absorbed water is now known to result in internal strains, facilitating the extraction of free monomers or polymerization residues in resin-based materials. Water molecules can be also clustered ${ }^{7,8}$ inducing a plasticization effect and softening of the surrounding matrix (that is, a lowering of the elastic modulus) ${ }^{9}$. Water is also responsible for chemical decomposition, such as the oxidation and hydrolysis of the resin matrix ${ }^{10}$. In a previous study, hardness was found to be negatively influenced by both curing tip distance and storage time ${ }^{11}$.

A well polymerized composite has been reported to ensure increased mechanical and chemical properties ${ }^{12}$. In contrast, today there is no agreement about the ideal power density needed to produce acceptable polymerization and

*e-mail: paulodalpino@yahoo.com hardness in resin composites ${ }^{13}$. Parameters as energy density, irradiance, light source, and exposure time are of particular interest since, in practice, are under control of the clinician ${ }^{14}$. Ideally, the light tip should be as close as possible to the composite surface in order to avoid light to be dissipated. However, some clinical situations represent a challenge to the utilization of this recommended polymerization technique, such as the accessibility of the light source, the direction of the light, preparation depth and surrounding tissues/materials ${ }^{15}$. In those cases, a reduced monomer conversion might occur. Resin conversion is important to ensure optimum mechanical properties in order to resist mechanical and chemical deterioration ${ }^{16}$. Depending on the clinical scenario, the amount of light penetrating the bulk material can be attenuated or scattered; as a consequence fewer molecules of camphorquinone are activated reducing the extent of reaction and also limiting the depth of cure ${ }^{17}$.

The hydrophilicity, mobility and kinetic parameters is determined by the composite composition ${ }^{16}$. BisGMA monomer contains pendant hydroxyl groups within its molecular structure ${ }^{18}$. Because of these polar groups, polymers made with this monomer are hydrophilic and prone to water sorption ${ }^{19}$. In this way, various strategies have been used to reduce the hydrophilicity of BisGMA-based 
composites $^{18}$. Ethoxylated bisphenol-A (BisEMA), a non-hydroxylated monomer, was then developed. BisEMA is less hydrophilic and exhibits a reduced viscosity ${ }^{18}$ when compared to that of BisGMA. Additionally, staining susceptibility of resin composite might be attributed to the degree of water sorption and hydrophilicity of matrix resin, that is, if the resin composite can absorb water it can also absorb other fluids like dyes, tea and coffee ${ }^{20}$. Color stability is an important parameter for composite restorations. Composite discoloration occurs due extrinsic and intrinsic factors ${ }^{21}$. Extrinsic factors include exposure to environmental factors including ambient and ultraviolet radiation $^{22}$, heat ${ }^{23}$, and water or food colorants ${ }^{20}$. Intrinsic factors include composition of composite matrix ${ }^{24}$, type of photoinitiator $^{13}$, and degree of conversion ${ }^{25}$.

This study evaluated the influence of different curing tip distances in the kinetics of water diffusion (water sorption-WSP, solubility-WSB, and net water uptake) and in the color stability of a commercial BisEMA-based resin composite. The results were compared to the values obtained when the curing tip was positioned closer to the polymerizing composite surface. The research hypotheses were: (1) there is no difference in the kinetics of water diffusion (sorption, solubility, and net water uptake) when a resin composite is photoactivated using different tip distances; (2) there is no difference in the color stability of resin composite immersed in a grape juice in comparison to immersion in distilled water, irrespective of the polymerization distance. Finally, (3) it was hypothesized that there would be no difference in the color stability over 4 weeks of evaluation times, irrespective of the storage media (distilled water and grape juice).

\section{Material and Methods}

A microhybrid resin composite (Z250, 3M ESPE; St Paul, MN, USA, shade A3) was selected for this study. Disc-shaped specimens were prepared in a Teflon mold ( $2.5 \mathrm{~mm}$ thick $\times 6.0 \mathrm{~mm}$ in diameter). Composite was inserted in bulk in the mold and confined between two opposing Mylar strips. After insertion, a polyester strip was applied to the surface of the unpolymerized material and a microscope slide was pressed against the composite surface to adapt the material completely to the inner portion of the mold. Not only the same restorative material volume was obtained, but also a flat top and bottom surfaces. The excess material was removed and the specimens were then photoactivated at the top surface. A quartz-tungsten-halogen (QTH) curing light at $640 \mathrm{~mW} . \mathrm{cm}^{-2}$ was used to polymerize the specimens (Ivoclar Vivadent Astralis 3, Schaan, Liechtenstein). Light intensity was monitored throughout the experiment to ensure that a consistent intensity was maintained. Specimens were photoactivated according to the different curing tip distances $(5,10$, and $15 \mathrm{~mm})$ used to polymerize the composite. The results were compared to the mean microhardness values obtained for the control group $(0 \mathrm{~mm})$. After polymerization, the specimens were removed from the molds and excess material was removed with a scalpel blade.

\subsection{Kinetic of water diffusion (water sorption, solubility, and net water uptake)}

Eight specimens were prepared for each experimental group (G1-0 mm, G2-5 mm, G3-10 mm, G4-15 mm). The specimens were repeatedly weighed every 24 hours, until a constant mass $\left(m_{l}\right)$ was obtained (i.e. a mass in which variation amounted to less than $0.2 \mathrm{mg}$ within any 24 hours period $)^{26}$. The thickness and diameter of the specimens were measured to the nearest $0.01 \mathrm{~mm}$, using a digital caliper (Absolute Digimatic, Mitutoyo, Tokyo, Japan), and these measurements were used to calculate the volume (V) of each specimen (in $\mathrm{mm}^{3}$ ). Specimens were then individually placed in test tubes (Eppendorf vials) containing $10 \mathrm{~mL}$ of distilled water ( $\mathrm{pH} 7.2)$ at $37^{\circ} \mathrm{C}$. Once each storage time interval, up to 120 days had passed, the tubes were removed from the oven and left to equilibrate at room temperature for 30 minutes. The specimens were then washed in running water, gently wiped with a soft absorbent paper, weighed by means of an analytical balance $\left(m_{2}\right)$ until a constant mass was obtained and returned to vials containing $10 \mathrm{~mL}$ of fresh distilled water. Following the 120 days of storage, the specimens were dried inside a desiccator containing fresh silica gel and weighed daily until a constant mass $\left(m_{3}\right)$ was obtained (as previously described). The initial mass determined after the first desiccation process $\left(m_{l}\right)$ was used to calculate the change in mass after each fixed time interval of the 120 days of storage in water. Changes in mass were plotted against the storage time in order to obtain the kinetics of water sorption for the entire period of water storage. The water sorption (WS) and solubility $(S L)$ were calculated as follows ${ }^{7}$ :

$W S=\frac{m_{2}-m_{3}}{V} S L=\frac{m_{1}-m_{3}}{V}$

where $m_{1}$ refers to the initial dry constant mass $(\mathrm{mg})$ prior to immersion in water; $m_{2}$ describes the mass $(\mathrm{mg})$ after water immersion at various time periods; $m_{3}$ is the mass $(\mathrm{mg})$ after drying the specimens that had reached their maximum water sorption and $V$ refers to the specimen's volume in $\mathrm{mm}^{3}$. Net water uptake (\%) was also calculated as the sum of water sorption and solubility. Data were subjected to ANOVA and Tukey pos-hoc test at a pre-set alpha of 0.05 .

\subsection{Color stability}

Sixteen specimens were prepared for each experimental group (G1-0 mm, G2-5 mm, G3-10 mm, G4-15 mm): 8 discs to control group (immersion in water) and 8 discs to experimental group (immersion in a grape juice). After 24 hours of storage into lightproof recipients, the top side of the specimens was polished with \#600 (30 seconds) and \#1200 grit SiC papers (30 seconds), followed by diamond paste (60 seconds) to standardize the surface roughness. An indelible mark was made on the specimen to ensure that the shade readings were repeatedly performed at the same spot. The specimen color readings were analyzed with a portable reflection spectrophotometer (Color Guide 45/0, BYK-Gardner GmbH, Geretsried, Germany) employed in an optical geometry $45^{\circ} / 0^{\circ}$ against a white background. The color was evaluated according to the color system CIE-L*a*b*, in which ' $L$ ' indicates color luminosity (0-black 
to 100 -white): $a^{*}$ determines the amount of red (positive values) and green (negative values); $b^{*}$ determines the amount of yellow (positive values) and blue (negative values).

Initial color readings (baseline) were made at the top surface of the specimens. Then, the specimens were fixed to an EVA device allowing only the top surfaces to be in touch with either distilled water or the grape juice tested. Half of the specimens of each group were immersed twice a day in the same volume of a grape juice $(\mathrm{pH} 2.8$, Vinícula Salton, Porto Alegre, RS, Brazil,) for 10 minutes each immersion time. Then, the specimens were stored in distilled water at room temperature for the remaining time. Specimens from the control group were kept in distilled water during the experimental period. The specimens were kept at room temperature in the whole process and the solutions were daily replaced. Readings were also performed after 1, 7, 14, and 28 days of immersion.

After removal from the solutions, the sample was blot-dried with an absorbent paper prior to the color measurement. At each time period, the color values of each specimen was measured again, and the color change value $\left(\Delta \mathrm{E}^{*} \mathrm{ab}\right)$ calculated as follows:

$\Delta \mathrm{E}^{*} \mathrm{ab}=\left[(\Delta \mathrm{L} *)^{2}+\left(\Delta \mathrm{a}^{*}\right)^{2}+\left(\Delta \mathrm{b}^{*}\right)^{2}\right]^{1 / 2}$

Data were submitted to three-way ANOVA (factors were: light tip distance, media, and immersion time) and Tukey's test, at a pre-set alpha of 0.05 .

\subsection{SEM observation}

In order to evaluate the resin composite's microstructure, four discs of resin composite were prepared using Teflon molds (6 $\mathrm{mm}$ in diameter, $2.5 \mathrm{~mm}$ thick). After photoactivation, the specimens were immersed in acetone p.a. (99.5\%, Fisher Scientific, Fair Lawn, NY, USA) for 24 hours and then dehydrated in silica gel for 2 hours. Next, the processed specimens were sputter-coated (40 mA for 120 seconds) with gold/palladium (SCD 050; Balzers, Schaan, Liechtenstein) in order to characterize the inorganic phase of the resin composites by means of SEM (JSM 5600LV, JEOL, Tokyo, Japan) under secondary electron mode, operated at $25 \mathrm{kV}$. Representative images of selected regions of the specimens were taken in order to observe the morphological aspect of the composite surface.

\section{Results}

\subsection{Kinetics of water diffusion}

Water sorption and solubility means $\left(\mu \mathrm{g} \cdot \mathrm{mm}^{-3}\right)$ of the experimental groups are described in Table 1. The groups in which the composite was photoactivated at 10 and $15 \mathrm{~mm}$ of distance showed significantly higher water sorption compared to that of $0 \mathrm{~mm}(\mathrm{p}<0.05)$. No significance was noted when the polymerization was performed at $5 \mathrm{~mm}$ in comparison to the control group ( $\mathrm{p}>0.05)$. Regarding the solubility parameter, only the group photoactivated at $15 \mathrm{~mm}$ of distance exhibited significantly higher solubility mean $\left(3.68 \mu \mathrm{g} . \mathrm{mm}^{-3}\right)$ when compared to that of the control group $\left(-1.51 \mu \mathrm{g} . \mathrm{mm}^{-3}\right)(\mathrm{p}<0.05)$. The highest $\%$ of net water uptake was noted in the group photoactivated at $15 \mathrm{~mm}$ of distance. There was a progressively increase in the percentage of net water uptake as the distance increased (from 3.13 to 4.11, groups 0 and $15 \mathrm{~mm}$, respectively).

Mass variation curves for the 120 days of immersion in water are presented in Figure 1. All experimental groups showed a continuous increase of mass reaching equilibrium between the $90^{\text {th }}$ and the $120^{\text {th }}$ day of storage in water. When mass gain (i.e. water sorption) and mass loss (i.e. solubility) of resin composite disks were plotted against time, the lowest water sorption was determined for the group $0 \mathrm{~mm}$ (at 'A'). Group $15 \mathrm{~mm}$ exhibited the highest mass loss (at ' $\mathrm{B}$ ').

\subsection{Color stability}

Statistical analysis revealed a significant interaction between factors 'media' $\times$ 'distance' $(\mathrm{P}=0.00539)$ and 'media' and 'time' $(\mathrm{P}=0.00482)$. Results are shown on Table 2 and 3. When the means $\Delta \mathrm{E}^{*}$ of the experimental groups in distilled water were compared (Table 2), significance was only noted when the mean of Group $15 \mathrm{~mm}$ (0.96) was compared to $5 \mathrm{~mm}(0.78)(\mathrm{p}>0.05)$; however no significance was observed when the experimental groups $(5 \mathrm{~mm}, 10 \mathrm{~mm}$ and $15 \mathrm{~mm})$ were compared to the control group $(0 \mathrm{~mm})(\mathrm{p}>0.05)$. When the $\Delta \mathrm{E}^{*}$ of the specimens immersed in grape juice were compared, a significance was only noted when the mean of Group $15 \mathrm{~mm}$ (4.05) was compared to $0 \mathrm{~mm}(3.02)(\mathrm{p}<0.05)$. According to the results seen in the Table 3, no significance was noted in the means of $\Delta \mathrm{E}^{*}$ when the immersion times in distilled water were compared. On the other hand, in grape juice, the longer the immersion times, the higher the color alteration of the specimens $(\mathrm{p}<0.05)$. Significant differences between times were noted in the specimens immersed in grape juice $(\mathrm{p}<0.05)$.

\subsection{SEM observation}

Specimens stored in the grape juice presented more evident morphology alterations when compared to specimens stored in distilled water (Figures $2 \mathrm{a}$ to h). It was

Table 1. Water sorption after 120 days of water storage and solubility.

\begin{tabular}{cccccc}
\hline $\begin{array}{c}\text { Distance } \\
(\mathbf{m m})\end{array}$ & $\begin{array}{c}\text { Water sorption } \\
\left(\boldsymbol{\mu g} . \mathbf{m m}^{-3}\right)\end{array}$ & $(\boldsymbol{\%})$ & $\begin{array}{c}\text { Solubility } \\
\left(\boldsymbol{\mu g . m m ^ { - 3 } )}\right.\end{array}$ & $(\boldsymbol{\%} *)$ & $\begin{array}{c}\text { Net water } \\
\text { uptake }(\boldsymbol{\%})^{* * *}\end{array}$ \\
\hline 0 & $29.8(1.7)^{\mathrm{A}}$ & 2.98 & $-1.5(1.3)^{\mathrm{A}}$ & 0.15 & 3.13 \\
5 & $30.8(0.8)^{\mathrm{AB}}$ & 3.08 & $-1.0(1.4)^{\mathrm{A}}$ & 0.10 & 3.18 \\
10 & $32.3(1.2)^{\mathrm{B}}$ & 3.23 & $-0.17(0.9)^{\mathrm{A}}$ & 0.01 & 3.24 \\
15 & $37.4(2.2)^{\mathrm{C}}$ & 3.74 & $3.7(1.4)^{\mathrm{B}}$ & 0.37 & 4.11 \\
\hline
\end{tabular}

Different capital letters in columns: significant $(\mathrm{p}<0.05) . * 29.8 \mu \mathrm{g} \cdot \mathrm{mm}^{-3}=0.0298 \mathrm{mg} \cdot \mathrm{mm}^{-3} \times 100=2.98 \mathrm{mg} .100 \mathrm{~mm}{ }^{-3}=2.98 \%$. $* *$ Net water uptake is the sum of water sorption and solubility $(\%)$. 


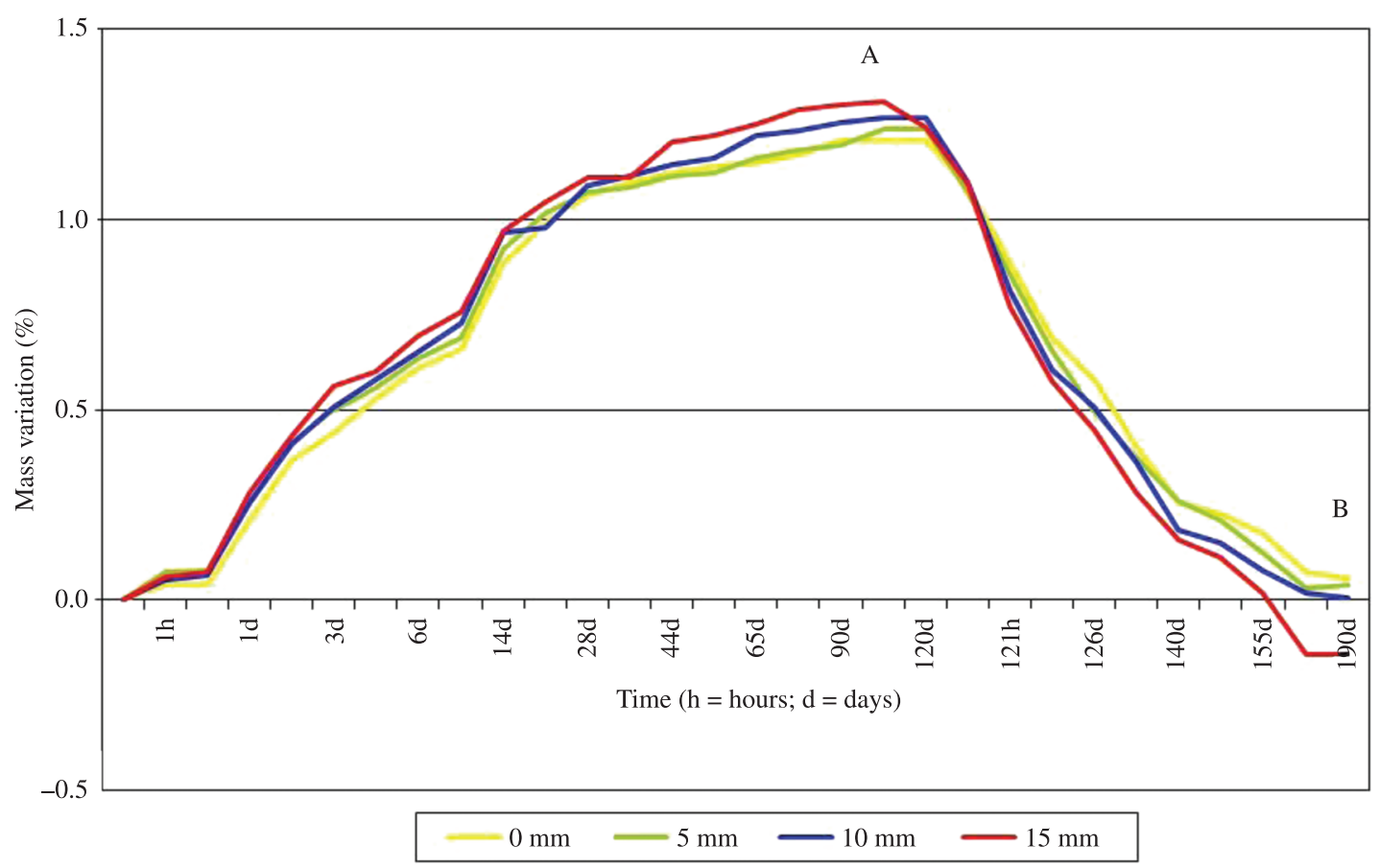

Figure 1. Changes in mass of resin composites over the water sorption/solubility test.

Table 2. Means of $\Delta \mathrm{E}^{*}$ (st. dv.) as a function of the immersion media.

\begin{tabular}{cccc}
\hline & \multicolumn{2}{c}{ Immersion media } \\
\cline { 1 - 1 } \cline { 3 - 3 } Distance $(\mathbf{m m})$ & & Distilled water & Grape juice \\
\cline { 1 - 2 } $\mathbf{0}$ & $0.78(0.37)^{\mathrm{Aba}}$ & $3.02(1.19)^{\mathrm{Ab}}$ \\
$\mathbf{5}$ & & $0.61(0.24)^{\mathrm{Ba}}$ & $3.48(1.40)^{\mathrm{ABb}}$ \\
$\mathbf{1 0}$ & & $0.89(0.43)^{\mathrm{Aba}}$ & $3.67(1.18)^{\mathrm{Ab}}$ \\
$\mathbf{1 5}$ & & $0.96(0.40)^{\mathrm{Aa}}$ & $4.05(1.39)^{\mathrm{Bb}}$ \\
\hline
\end{tabular}

Different small letters in rows and capital letters in columns: significant $(\mathrm{p}<0.05)$.

Table 3. Means of $\Delta \mathrm{E}^{*}$ (st. dv.) as a function of the time.

\begin{tabular}{cccc}
\hline & \multicolumn{2}{c}{ Immersion media } \\
\cline { 1 - 2 } \cline { 3 - 3 } Time (days) & & Distilled water & Grape juice \\
\cline { 1 - 2 } $\mathbf{7}$ & $0.77(0.36)^{\mathrm{Aa}}$ & $2.19(0.69)^{\mathrm{Ab}}$ \\
$\mathbf{1 4}$ & & $0.79(0.39)^{\mathrm{Aa}}$ & $2.89(0.73)^{\mathrm{Bb}}$ \\
$\mathbf{2 1}$ & & $0.85(0.41)^{\mathrm{Aa}}$ & $4.16(0.84)^{\mathrm{Cb}}$ \\
$\mathbf{2 8}$ & & $0.84(0.39)^{\mathrm{Aa}}$ & $4.99(0.82)^{\mathrm{Db}}$ \\
\hline
\end{tabular}

Different small letters in rows and capital letters in columns: significant $(\mathrm{p}<0.05)$.

noted that, the higher the light tip distance, the higher the morphological alterations.

\section{Discussion}

Resin degradation may be associated with either volumetric changes such as swelling, physical changes such as plasticization, chemical changes such as oxidation and hydrolysis ${ }^{9}$. Figure 1 demonstrates that the resin composite had a continuous increase in mass as the storage in water was initiated (considering $m_{1}$ as the baseline mass). Only the group $10 \mathrm{~mm}$ exhibited a final mass $\left(m_{3}\right)$ similar to that observed at the baseline $\left(m_{1}\right)$ (Figure 1, in 'b'). Reasons that explain the fact that the experimental groups exhibited different final mass relies on the ability of the polymer network to release unreacted monomers through nanovoids in the material ${ }^{27}$, showing a decrease in mass within a short time of water immersion. Based on a previous study ${ }^{11}$, composite can degrade very differently after water storage and it is influenced by the degree of conversion and the quantity of pendant molecules existing within the polymer network ${ }^{26}$. The quality of the network that forms during polymerization can dictate the extent to which molecular uptake and swelling occur when a polymer is submerged in a solvent ${ }^{9}$. Besides, the higher the porosities, the easier the transport of water molecules in and out of the composites, thus leading to enhanced water uptake and monomer elution ${ }^{9}$. Malacarne et al. ${ }^{26}$ pointed out that the methacrylate-based materials usually present a spatial heterogeneity, with densely cross-linked areas and other loosely cross-linked. According to the results of the present study, varying the distance at which the composites are photoactivated, favored the presence of poorly polymerized areas that were infiltrated, increasing the mass. On the other hand, the unreacted monomers and low molecular weight polymers that are entrapped in the microgels and/or in the voids can leach out. This may reduce the mass of the specimens. Since the mass variation is the net result of both the increase in mass due to water penetration, and the decrease in mass due to elution of low molecular 


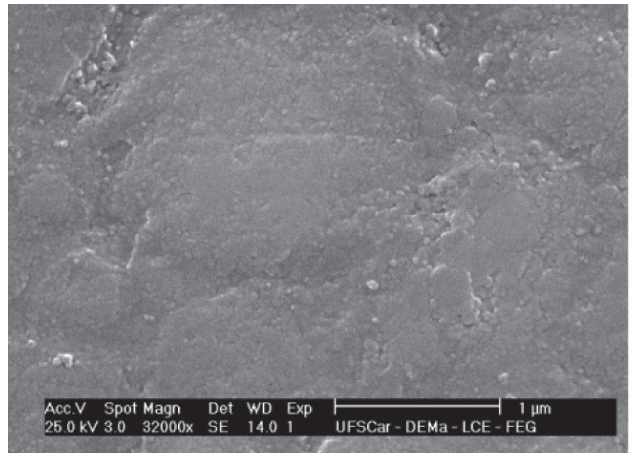

(a)

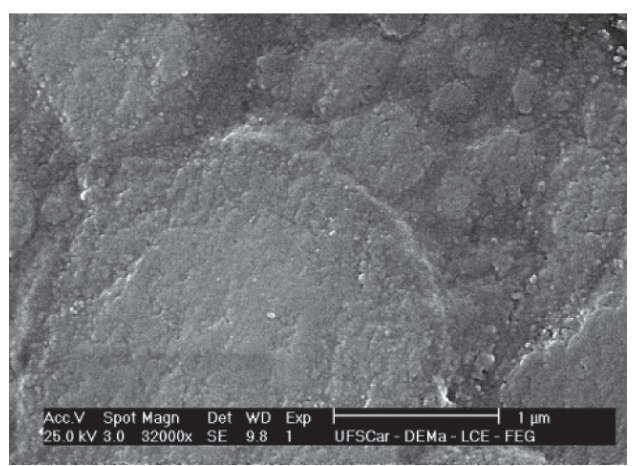

(c)

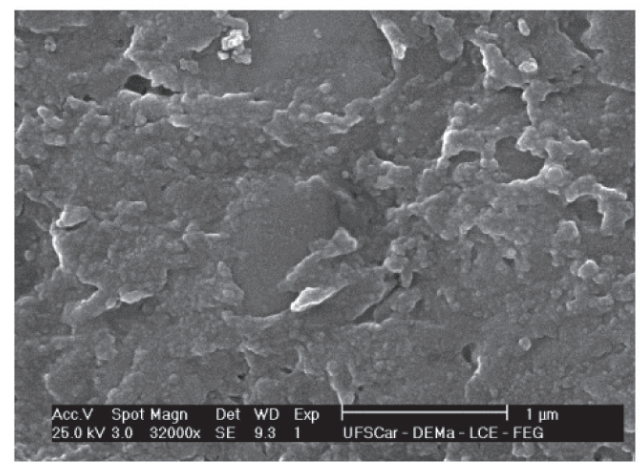

(e)

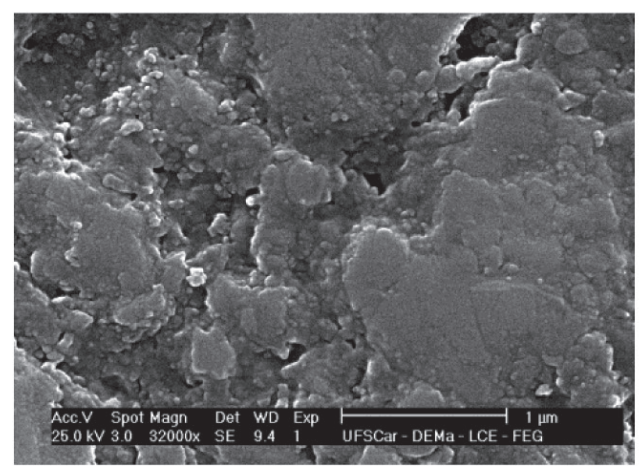

(g)

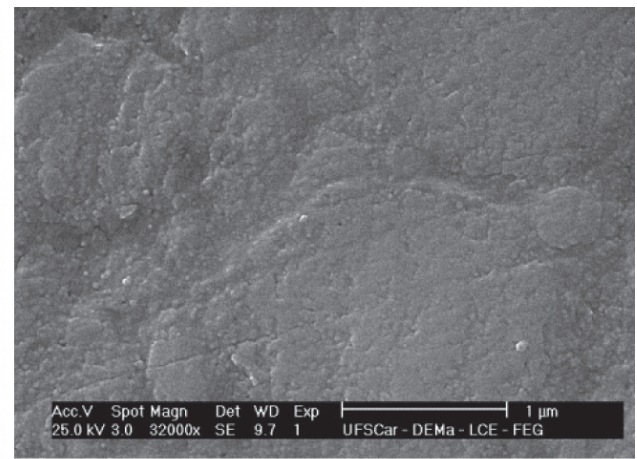

(b)

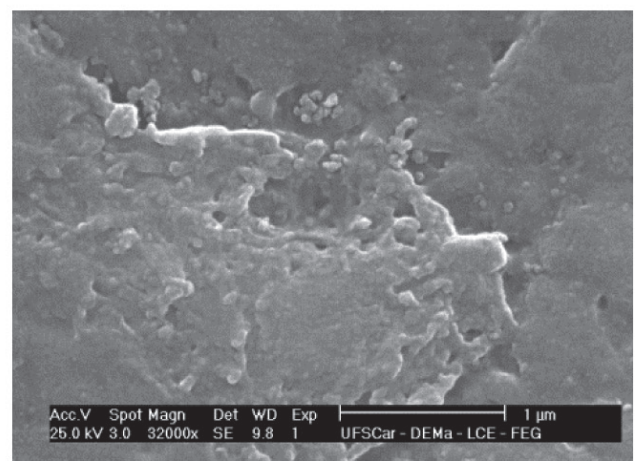

(d)

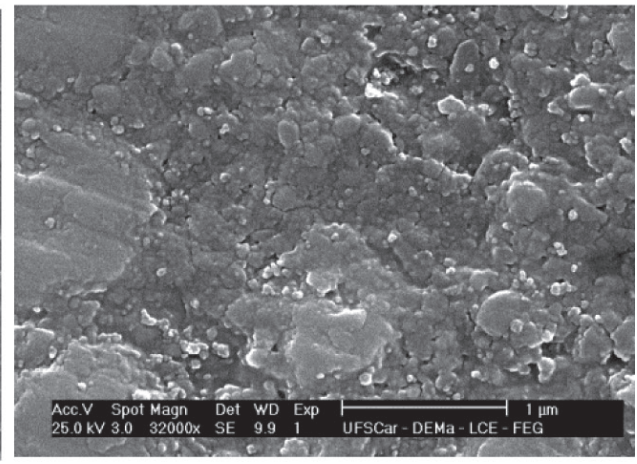

(f)

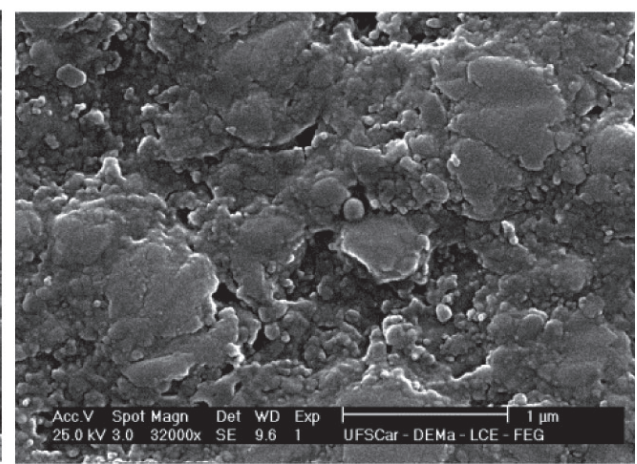

(h)

Figure 2. Representative backscattered SEM images of the morphological aspect of the composite surface photoactivated (magnification $3200 \times$ ). From a to d: photomicrograph of morphological aspect of the composite surface when immersed in distilled water as a function of the photoactivation distance ( 0 to $15 \mathrm{~mm}$ ). From e to h: photomicrograph of morphological aspect of the composite surface when immersed in the grape juice as a function of the photoactivation distance ( 0 to $15 \mathrm{~mm}$ ). It was evident the alteration of the composite surface when immersed in the grape juice. The higher the tip distance, the higher the presence of grooves in the composite surface. 
weight material, it is difficult to quantify the magnitude of entrapped water ${ }^{7}$.

The increased water sorption in the experimental groups photoactivated at 10 and $15 \mathrm{~mm}$ may be associated with a less cross-linked polymer structure. Polymerization at reduced rate (lower power density) may lead to a more linear polymer structure because relatively few growth centers are formed ${ }^{28}$. Providing a higher energy density several growth polymerizing areas are formed, leading to a more cross-linked polymer structure. According to Ferracane ${ }^{9}$, composites with high cross-linking density have reduced solvent uptake and swelling due to the limited space and pathways available for the solvent to diffuse within the polymer structure. Regarding the solubility parameter, a significantly higher mean was found for the group photoactivated at $15 \mathrm{~mm}$ compared to the control group. Negative values were observed for solubility in groups 0,5 , and $10 \mathrm{~mm}$, which generally occur when sorption exceeds the solubility, indicating that the water molecules were entrapped within the specimens, interfering in the results.

According to ISO 4049 for dental restorative resins, a resin must display a water sorption lower than $50 \mu \mathrm{g} . \mathrm{mm}^{-3}$ and solubility lower than $5 \mu \mathrm{g} . \mathrm{mm}^{-3}$ after a seven-day time period in order to be considered suitable for use as dental material $^{7}$. The results of the present study for water sorption and solubility were inferior to that of required in the ISO, irrespective of the period of time in which the composite was tested (120 days). On the other hand, this study demonstrated that the behavior in terms of water sorption continues until an equilibrium was reached. The analysis of the kinetics of water diffusion, which was determined from the association of water sorption and solubility, actually correlated with the behavior of the experimental groups evaluated. The variation in mass, due to both water penetration and the elution of low molecular weight material, revealed the resulting net water uptake (in \%) to be higher, the further the distance from the composite surface. Since water sorption and solubility occur simultaneously ${ }^{29}$, the sum of both values was used to estimate the total water uptake. These values ranged from 3.13 to $4.11 \%$ among the experimental groups. Thus, the first hypothesis, that no difference in the kinetics of water diffusion when the resin composite was photoactivated using different tip distances, was rejected.

Kinetics and the extent of polymerization were shown to considerably change among experimental groups tested under various light tip distances. Consequently, it has been found that the curing distance and the immersion time affects surface hardness ${ }^{11}$. The efficiency of polymerization may also influence the composite discoloration, since the amount of residual monomers available to form colored degraded products is reduced in well polymerized composites ${ }^{30}$. In the present study, the color change became more intensive as immersion time increased. $\Delta \mathrm{E}$ value in distilled water varied from 0.78 to 0.96 for the specimens immersed in distilled water and from 3.02 to 4.05 in grape juice (from 0 to $15 \mathrm{~mm}$, respectively). In addition, the color changes were significantly higher in the specimens immersed in the grape juice, irrespective of the evaluation time. Considering the value $\Delta \mathrm{E}=3.3$ as an acceptable value in which a higher variation would represent a clinically relevant alteration ${ }^{31}$, it was found that after 21 days of immersion in grape juice the color change surpassed this reference value. Thus, the immersion time was considered a critical factor in the color stability of the resin composite tested. Considering the factors 'distance' and 'media', the statistical analysis revealed significance only between the group photoactivated at $15 \mathrm{~mm}$ of distance compared to control group. On the other hand, considering 3.3 as the reference value, a clinically unacceptable value would be obtained for the specimens of group $5 \mathrm{~mm}, 10 \mathrm{~mm}$, and $15 \mathrm{~mm}$, immersed in the grape juice. Furthermore, considering that the values of $\Delta \mathrm{E}$ higher than 1 are considered as visually perceptible ${ }^{31}$, the color stability of the specimens immersed in water were similar to that of the control group, irrespective of the distance of photoactivation. In the present study, sample discoloration by grape juice tended to follow the evolution of water sorption. In contrast, water sorption by itself did not seem to alter the color of composite to a considerable extent. It has been claimed that, in the absence of external staining sources, internal shade alterations seems to be mainly related to the influence of aging ${ }^{32}$.

The optical properties of a resin composite restorations change over time, thus changing its clinical appearance. Many factors are related to the discoloration of the composite material, such as the modification in the resin matrix and at the interface of matrix and fillers 9 . With time, there is chemical decomposition such as oxidation and hydrolysis of the resin matrix. Depending on the extent of water uptake, the hoop stresses around the filler particles can be reduced, facilitating filler pulling-out by breaking down the resin filler bond ${ }^{9,33}$, or by causing the erosion of the surface of filler particles ${ }^{9}$. In addition, the color stability is hampered by aging under various physical-chemical conditions in the oral cavity such as thermal changes and humidity ${ }^{3}$. The absorption of extrinsic stains in the composite surface may be also a cause of discoloration ${ }^{9}$. These factors help to explain why composite restorations can change over time, mainly due to external stain from beverages or foods. New formulations of monomers were developed by modifying the chemical structure of certain monomers and/or replacing them. The structure of BisEMA is similar to that of BisGMA, aside from the absence of hydroxyl groups ${ }^{16}$. Replacing BisGMA with BisEMA in composites containing TEGDMA resulted in a higher conversion but no improvement in flexural and diametral tensile strengths ${ }^{34}$. Another study ${ }^{16}$ also demonstrated that mixtures of BisGMA and TEGDMA present an increased crosslink density and a higher degree of conversion than what is observed for mixtures of BisGMA and BisEMA. The lower molecular weight of TEGDMA and the synergic effect with BisGMA have been explained to influence the kinetic parameters contributing to a higher conversion. Furthermore, an internal plasticizing effect has been attributed to BisEMA as a result of its high molecular weight, which reduces the crosslink density of the polymer ${ }^{35}$. The results of the present study demonstrated that an extreme curing tip distance results in a higher the color change, highlighted when immersed in the grape juice.

SEM analysis revealed sites of filler debonding especially in the group of specimens photoactivated at higher distances and immersed in the grape juice. It has been 
claimed that the most probable site for accommodation of water is the interface between the inorganic filler particle and the polymer matrix ${ }^{36}$. According to this study, water diffuses through the resin matrix and attacks the fillers. First, the surface layer of the filler is attacked by stress corrosion, and, as a result, complete or partial filler debonding occurs, leading to degradation sites. Variations in the water uptake at the interface seem to be dependent on the nature of the filler particles, the use of a coupling agent and the method of polymerization ${ }^{26,29,35}$. This fact was confirmed by the presence of debonding superficial areas especially in the $15 \mathrm{~mm}$ group.

It is important to emphasize the importance of establishing a correlation between in vitro and in vivo tests, since the reproduction of the oral environment in the laboratory is difficult. It can be argued that the composites are not subjected to staining media for such a long period of time. On the other hand, it is important to evaluate the

\section{References}

1. Fabre HS, Fabre S, Cefaly DF, De Oliveira Carrilho MR, Garcia FC and Wang L. Water sorption and solubility of dentin bonding agents light-cured with different light sources. Journal of Dentistry. 2007; 35(3):253-8. PMid:17045723. http://dx.doi. org/10.1016/j.jdent.2006.09.002

2. Kilinc E, Antonson SA, Hardigan PC and Kesercioglu A. Resin cement color stability and its influence on the final shade of all-ceramics. Journal of Dentistry. 2011; 39 Suppl 1(e30-6). PMid:21241766. http://dx.doi.org/10.1016/j.jdent.2011.01.005

3. Furuse AY, Gordon K, Rodrigues FP, Silikas N and Watts DC. Colour-stability and gloss-retention of silorane and dimethacrylate composites with accelerated aging. Journal of Dentistry. 2008; 36(11):945-52. PMid:18778884. http://dx.doi. org/10.1016/j.jdent.2008.08.001

4. Vrochari AD, Eliades G, Hellwig E and Wrbas KT. Water sorption and solubility of four self-etching, self-adhesive resin luting agents. Journal of Adhesive Dentistry. 2010; 12(1):39-43. PMid:20155229.

5. Mese A, Burrow MF and Tyas MJ. Sorption and solubility of luting cements in different solutions. Dental Materials Journal. 2008; 27(5):702-9. PMid:18972787. http://dx.doi. org/10.4012/dmj.27.702

6. Santos C, Clarke RL, Braden M, Guitian F and Davy KW. Water absorption characteristics of dental composites incorporating hydroxyapatite filler. Biomaterials. 2002; 23(8):1897-904. http://dx.doi.org/10.1016/S0142-9612(01)00331-3

7. Sideridou I, Achilias DS, Spyroudi C and Karabela M. Water sorption characteristics of light-cured dental resins and composites based on bis-ema/pcdma. Biomaterials. 2004; 25(2):367-76. http://dx.doi.org/10.1016/ S0142-9612(03)00529-5

8. Kanchanavasita W, Anstice HM and Pearson GJ. Water sorption characteristics of resin-modified glass-ionomer cements. Biomaterials. 1997; 18(4):343-9. http://dx.doi.org/10.1016/ S0142-9612(96)00124-X

9. Ferracane JL. Hygroscopic and hydrolytic effects in dental polymer networks. Dental Materials. 2006; 22(3):211-22. PMid:16087225. http://dx.doi.org/10.1016/j. dental.2005.05.005

10. Dhanpal P, Yiu CK, King NM, Tay FR and Hiraishi N. Effect of temperature on water sorption and solubility of dental restorative material's stability in order to obtain increased mechanical and chemical properties, estimating the longevity and clinical success. According to the present study, special attention should be made to obtaining a optimal resin polymerization by polymerizing the composite at closer surface distance.

\section{Conclusions}

Based on the employed methodology and the results, it may be concluded that different light tip distances influence the kinetic of water diffusion. The color stability of the tested composite is also influenced; the higher the distance, the higher the color change. Immersion media also influences the color change. Specimens immersed in the grape juice present higher color change that significantly increases with time. adhesive resins. Journal of Dentistry. 2009; 37(2):122-32. PMid:19062151. http://dx.doi.org/10.1016/j.jdent.2008.10.004

11. Svizero NR, Carvalho VF, Bechtold J, Alonso RC, Atta MT and D'Alpino PH. Hydrolytic degradation of a resin composite as a function of the curing tip distance and aging. Materials Research. 2011; 14(4):541-46. http://dx.doi.org/10.1590/ S1516-14392011005000084

12. Felix CA and Price RB. The effect of distance from light source on light intensity from curing lights. Journal of Adhesive Dentistry. 2003; 5(4):283-91. PMid:15008335.

13. D'Alpino PH, Svizero NR, Pereira JC, Rueggeberg FA, Carvalho RM and Pashley DH. Influence of light-curing sources on polymerization reaction kinetics of a restorative system. American Journal of Dentistry. 2007; 20(1):46-52. PMid:17380808.

14. Halvorson RH, Erickson RL and Davidson CL. Energy dependent polymerization of resin-based composite. Dental Materials. 2002; 18(6):463-9. http://dx.doi.org/10.1016/ S0109-5641(01)00069-0

15. Emami N, Soderholm KJ and Berglund LA. Effect of light power density variations on bulk curing properties of dental composites. Journal of Dentistry. 2003; 31(3):189-96. http:// dx.doi.org/10.1016/S0300-5712(03)00015-0

16. Goncalves F, Kawano Y, Pfeifer C, Stansbury JW and Braga RR. Influence of bisgma, tegdma, and bisema contents on viscosity, conversion, and flexural strength of experimental resins and composites. European Journal of Oral Sciences. 2009; 117(4):442-6. PMid:19627357. http://dx.doi. org/10.1111/j.1600-0722.2009.00636.x

17. Rueggeberg F. Contemporary issues in photocuring. Compendium of Continuim Education in Dentistry. 1999; 25(Supl):4-15.

18. Kerby RE, Knobloch LA, Schricker S and Gregg B. Synthesis and evaluation of modified urethane dimethacrylate resins with reduced water sorption and solubility. Dental Materials. 2009; 25(3):302-13. PMid:18799211. http://dx.doi. org/10.1016/j.dental.2008.07.009

19. Shobha HK, Sankarapandian M, Kalachandra S, Taylor DF and McGrath JE. Structure property relationship among novel dental composite matrix resins. Journal of Materials Science Materials in Medicine. 1997; 8(6):385-9. PMid:15348741. http://dx.doi.org/10.1023/A:1018541102275 
20. Bagheri R, Burrow MF and Tyas M. Influence of foodsimulating solutions and surface finish on susceptibility to staining of aesthetic restorative materials. Journal of Dentistry. 2005; 33(5):389-98. PMid:15833394. http://dx.doi. org/10.1016/j.jdent.2004.10.018

21. Yazici AR, Celik C, Dayangac B and Ozgunaltay G. The effect of curing units and staining solutions on the color stability of resin composites. Operative Dentistry. 2007; 32(6):616-22. PMid:18051013. http://dx.doi.org/10.2341/07-3

22. Kolbeck C, Rosentritt M, Lang R and Handel G. Discoloration of facing and restorative composites by uv-irradiation and staining food. Dental Materials. 2006; 22(1):63-8. PMid:15993940. http://dx.doi.org/10.1016/j.dental.2005.01.021

23. Ferracane JL, Moser JB and Greener EH. Ultraviolet lightinduced yellowing of dental restorative resins. Journal of Prosthetic Dentistry. 1985; 54(4):483-7. http://dx.doi. org/10.1016/0022-3913(85)90418-4

24. Calheiros FC, Sadek FT, Braga RR and Cardoso PE. Polymerization contraction stress of low-shrinkage composites and its correlation with microleakage in class v restorations. Journal of Dentistry. 2004; 32(5):407-12. PMid:15193790. http://dx.doi.org/10.1016/j.jdent.2004.01.014

25. Peutzfeldt A and Asmussen E. The effect of postcuring on quantity of remaining double bonds, mechanical properties, and in vitro wear of two resin composites. Journal of Dentistry. 2000; 28(6):447-52. http://dx.doi.org/10.1016/ S0300-5712(00)00021-X

26. Malacarne J, Carvalho RM, De Goes MF, Svizero N, Pashley $\mathrm{DH}$, Tay FR et al. Water sorption/solubility of dental adhesive resins. Dental Materials. 2006; 22(10):973-80. PMid:16405987. http://dx.doi.org/10.1016/j.dental.2005.11.020

27. Brazel CS and Peppas NA. Dimensionless analysis of swelling of hydrophilic glassy polymers with subsequent drug release from relaxing structures. Biomaterials. 1999; 20(8):721-32. http://dx.doi.org/10.1016/S0142-9612(98)00215-4

28. Asmussen E and Peutzfeldt A. Polymer structure of a lightcured resin composite in relation to distance from the surface.
European Journal of Oral Sciences. 2003; 111(3):277-9. PMid:12786961. http://dx.doi.org/10.1034/j.16000722.2003.00044.x

29. Ito S, Hoshino T, Iijima M, Tsukamoto N, Pashley DH and Saito T. Water sorption/solubility of self-etching dentin bonding agents. Dental Materials. 2010; 26(7):617-26. PMid:20382415. http://dx.doi.org/10.1016/j.dental.2010.03.001

30. Samra AP, Pereira SK, Delgado LC and Borges CP. Color stability evaluation of aesthetic restorative materials. Brazilian Oral Research. 2008; 22(3):205-10. PMid:18949304. http:// dx.doi.org/10.1590/S1806-83242008000300003

31. Mutlu-Sagesen L, Ergun G, Ozkan Y and Semiz M. Color stability of a dental composite after immersion in various media. Dental Materials Journal. 2005; 24(3):382-90. PMid:16279728. http://dx.doi.org/10.4012/dmj.24.382

32. Dietschi D, Campanile G, Holz J and Meyer JM. Comparison of the color stability of ten new-generation composites: An in vitro study. Dental Materials. 1994; 10(6):353-62. http:// dx.doi.org/10.1016/0109-5641(94)90059-0

33. Martin N, Jedynakiewicz NM and Fisher AC. Hygroscopic expansion and solubility of composite restoratives. Dental Materials. 2003; 19(2):77-86. http://dx.doi.org/10.1016/ S0109-5641(02)00015-5

34. Stansbury JW. Synthesis and evaluation of new oxaspiro monomers for double ring-opening polymerization. Journal of Dental Research. 1992; 71(7):1408-12. PMid:1629456. http:// dx.doi.org/10.1177/00220345920710070901

35. Sideridou I, Tserki V and Papanastasiou G. Study of water sorption, solubility and modulus of elasticity of light-cured dimethacrylate-based dental resins. Biomaterials. 2003; 24(4):655-65. http://dx.doi.org/10.1016/ S0142-9612(02)00380-0

36. Kalachandra S and Wilson TW. Water sorption and mechanical properties of light-cured proprietary composite tooth restorative materials. Biomaterials. 1992; 13(2):105-9. http://dx.doi. org/10.1016/0142-9612(92)90004-8 